\title{
DEVELOPMENT OF A SIMPLE, RAPID AND VALIDATED SPECTROPHOTOMETRIC METHOD FOR NITAZOXANIDE IN PHARMACEUTICAL FORMULATIONS AND COMPARISON WITH HPLC
}

\author{
Marcelo Donadel Malesuik*, Clésio Soldatelli Paim, Elfrides Eva Scherman Schapoval e Martin Steppe \\ Faculdade de Farmácia, Universidade Federal do Rio Grande do Sul, Av. Ipiranga 2752, 90610-000 Porto Alegre - RS, Brasil
}

Recebido em 2/5/09; aceito em 25/9/09; publicado na web em 25/2/10

\begin{abstract}
A rapid, economical, reproducible, and simple direct spectrophotometric method was developed and validated for the assay of nitazoxanide in pharmaceutical formulations. Nitazoxanide concentration was estimated in water at $345 \mathrm{~nm}$ and $\mathrm{pH} 4.5$. The method was suitable and validated for specificity, linearity, precision, and accuracy. There was no interference of the excipients in the determination of the active pharmaceutical ingredient. The proposed method was successfully applied in the determination of nitazoxanide in coated tablets and in powders for oral suspension. This method was compared to a previously developed and validated method for liquid chromatography to the same drug. There was no significative difference between these methods for nitazoxanide quantitation.
\end{abstract}

Keywords: Nitazoxanide; UV-spectrophotometry; method validation.

\section{INTRODUCTION}

Nitazoxanide (NTZ) (Figure 1) is a new antiparasitic drug agent of broad-spectrum. Its chemical structure is 2-acetyloxyl-N-(5-nitro2-thiazolyl) benzamide. ${ }^{1} \mathrm{NTZ}$ is a new nitrothiazole benzamide compound that is notable for its activity in treating both intestinal protozoal and helminthic intestinal infections. ${ }^{2}$ It was first described in 1975 by Jean Francois Rossignol and was initially developed as a veterinary antihelminthic with activity against intestinal nematodes, cestodes, and trematodes. ${ }^{1,3}$ In humans, NTZ was approved by US Food and Drug Administration (FDA) in 2002. ${ }^{3}$ The NTZ was been reported to be effective against a broad range of parasites, incluing Entamoeba histolytica, Cryptosporidium parvum, Giardia lamblia, Trichomonas vaginalis, Isospora belli, Ascaris lumbricoides, Taenia saginata, Taenia solium. ${ }^{3-5}$ Its precise mechanism of action is unknown, but studies have shown that NTZ inhibits pyruvate ferredoxin oxireductase (PFOR) enzyme-dependent electron transfer reactions essential to anaerobic energy metabolism in these organisms.,<smiles>CC(=O)Oc1ccccc1C(=O)Nc1ncc([N+](=O)[O-])s1</smiles>

Figure 1. Chemical structure of nitazoxanide

NTZ is currently available in coated tablets and powders for oral suspension. An official method for the determination of this drug in oral formulation has not been described yet. However, there are works describing the determination of NTZ and its metabolites in biological fluids by liquid chromatographiy (LC) and LC-mass spectrometry (LC-MS) ${ }^{7-9}$ Recently, methods for the estimation of NTZ in bulk and pharmaceuticals formulations were develope in visible spectrophotometry, ${ }^{10}$ high-performance thin-layer chromatographiy (HPTLC) and LC. ${ }^{11-14}$

\footnotetext{
*e-mail: marcelodonadel@gmail.com
}

Several of these methods require the use of hazardous and expensive chemicals, which make the process not only a challenge for the environment but also complex and time consuming. Chromatographic techniques are time consuming, costly and require expertise. The development of a simple and accurate UV-spectrophotometric method can provide a very useful alternative for routine analysis of pharmaceutical formulations..$^{15-18}$

In the current literature, there is no publication concerning UVspectrophotometric determination of NTZ. The purpose of this work is to present the development and validation of a simple, fast, and environmental friendly and direct UV-spectrophotometric method for routine analysis of the NTZ in coated tablets and powder for oral suspension. We also present the comparison of our results with those obtained from LC analysis.

\section{EXPERIMENTAL}

\section{Chemicals and reagents}

NTZ used as reference substance (assigned purity, 99.53\%) was kindly supplied by Shin Yang-Hangzhou Shinyang Samwoo Fine Chemical CO. (Ningbo, China). According to guidelines and USP pharmacopeia for the quality control of drugs the use of a reference substance with checked purity is mandatory. ${ }^{19,20}$ The NTZ standard in use was analyzed by analytical techniques such as: LC-MS spectrometry, differential scanning calorimetric (DSC), infrared absorption spectroscopy, and ${ }^{1} \mathrm{H}$ and ${ }^{13} \mathrm{C}$ nuclear magnetic ressonance spectroscopy. No impurities were found.

Nixoran ${ }^{\circledR}$ (manufactured by Roemmers, Buenos Aires, Argentina) coated tablets for oral administration (500 mg per tablet, excipients: maize starch, pregelatinized starch, hydroxypropyl methylcellulose, sodium starch glycollate, talc, magnesium stearate, triacetin, iron oxide yellow, titanium dioxide, polyethylene glycol 6000) and Alinia ${ }^{\circledR}$ (manufactured by Romark Laboratories, Tampa, FL, USA) powder for oral suspension (1.2 g per bottle, excipients: sodium benzoate, sucrose, xanthan gum, microcrystalline cellulose and carboxymethylcellulose sodium, anhydrous citric acid, sodium citrate dihydrate, acacia gum, sugar syrup, FD\&C Red \#40 and natural strawberry flavoring) were purchased. Chemicals of analytical reagent grade were used in our analysis. Acetonitrile and o-phosphoric acid were obtained from Merck (Darmstadt, Germany). Destilled water was used to prepare all solutions for the UV method. 


\section{Instrumentation and conditions}

Spectral and absorbance measurements were made with a UV-Vis Shimadzu model UV 160A, using $10 \mathrm{~mm}$ quartz cells and detection at $345 \mathrm{~nm}$.

\section{Standard solution preparation}

A stock solution of $100 \mu \mathrm{g} \mathrm{mL} \mathrm{m}^{-1} \mathrm{NTZ}$ reference substance was prepared by dissolving $10 \mathrm{mg}$ of drug in $100 \mathrm{~mL}$ of acetonitrile in a volumetric flask. An aliquot of $3 \mathrm{~mL}$ of this solution was transferred into $25 \mathrm{~mL}$ volumetric flask, marking up to volume with water previously adjusted to $\mathrm{pH} 4.5$ by addition of $o$-phosphoric acid $10 \%$ in order to give a final concentration of $12 \mu \mathrm{g} \mathrm{mL} \mathrm{m}^{-1}$ (working solution).

\section{Sample preparation}

Twenty tablets were weighed and crushed to a fine powder. An accurately weighed amount of tablet powder equivalent to $15 \mathrm{mg}$ of NTZ was transferred to a $100 \mathrm{~mL}$ volumetric flask with $50 \mathrm{~mL}$ of acetonitrile and sonicated for $10 \mathrm{~min}$, followed by adding the same solvent to make up the volume. After filtration, an aliquot of $2 \mathrm{~mL}$ of this solution was transferred into a $25 \mathrm{~mL}$ volumetric flask and marked up to volume with water at $\mathrm{pH} 4.5$ in order to produce a final concentration of $12 \mu \mathrm{g} \mathrm{mL}^{-1}$ (working solution). The same procedure was carried out in powder for oral suspension.

\section{Method validation}

The developed analytical method was validated following ICH guidelines and USP requirements. ${ }^{19,20}$

\section{Linearity}

Stock solution $\left(100 \mu \mathrm{g} \mathrm{mL}^{-1}\right)$ of NTZ was prepared in acetonitrile and distinct aliquots were transferred to several volumetric flasks and marked up to volume with water at $\mathrm{pH} 4.5$ in order to produce a final concentration of 2, 4, 8, 12, 16 and $20 \mu \mathrm{g} \mathrm{mL}^{-1}$. Each concentration was prepared in triplicate. The linearity was evaluated by linear regression analysis, which was calculated by the least square regression method.

\section{Specificity}

The evaluation of the specificity of the method was performed by preparing placebos of tablet as well as powder for oral suspension containing the same excipients of the commercial products. Placebo solutions (12 $\mu \mathrm{g} \mathrm{mL}^{-1}$ in theory) were prepared using the same procedure described for the Sample Preparations $(n=3)$. In a separate study, drug with the same concentration was prepared independently from pure drug stock and analyzed. All the solutions were scanned from 400 to $200 \mathrm{~nm}$ and checked for any interference in the absorbance at all tested wavelengths (Figures 1 and 2).

\section{Precision}

The precision of the method was determined by repeatability (intra-day precision) and intermediate precision (inter-day precision) and was expressed as relative standard deviation (RSD\%) of a series of measurement. The repeatability was evaluated by assaying six samples of each pharmaceutical formulation, at the same concentration (12 $\mu \mathrm{g} \mathrm{mL}^{-1}$ ) during the same day. The intermediate precision was studied by comparing the results obtained on three different days.

\section{Accuracy}

This parameter was determined by the recovery test, that consisted on adding known amounts of reference solution to the sample solutions (prepared according to "Sample preparation"). Aliquots of $0.5,1.0$, and $1.5 \mathrm{~mL}$ of NTZ standard solution $100 \mu \mathrm{g} \mathrm{mL}^{-1}$ were transfered to the sample solutions during the last dilution of the samples. The final concentration of reference standard in each level were: 2,4 , and $6 \mu \mathrm{g} \mathrm{mL} \mathrm{m}^{-1}$.

\section{Robustness}

Robustness of the proposed method was determined by changing the $\mathrm{pH}$ of the media in \pm 0.2 units and by maintaining the solutions at room temperature $\left(25 \pm 2{ }^{\circ} \mathrm{C}\right)$ for $3 \mathrm{~h}$ to test the stability of NTZ in the working diluent (water at $\mathrm{pH} 4.5$ ).

\section{LC apparatus and conditions}

The LC system consisted of a Shimadzu LC-10AD ${ }_{\mathrm{vP}}$ pump, a SPD-M10A $A_{\mathrm{VP}}$ Photo Diode Array (PDA), a SCL-10A ${ }_{\mathrm{VP}}$ system controller, CTO- $10 \mathrm{AC}_{\mathrm{VP}}$ column oven, SIL- $10 \mathrm{AD}_{\mathrm{VP}}$ auto injector, and a degasser module DGU-14A. Data were acquired and processed by Shimadzu Class-VP ${ }^{\circledR}$ V 6.14 software program (Shimadzu, Kyoto, Japan). The LC method previously developed and validated by our research group was used for comparison with the proposed spectrophotometric method ${ }^{14}$. The column utilized was a Phenomenex ${ }^{\circledR}$ (Torrance, CA, USA) Synergi Fusion $\mathrm{C}_{18}$ column ( $250 \mathrm{~mm}$ x $4.6 \mathrm{~mm}$,

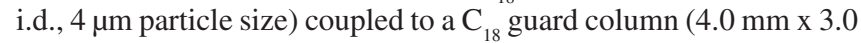
$\mathrm{mm}$, i.d., $4 \mu \mathrm{m})$. The Shimadzu LC system was operated isocratically at $25{ }^{\circ} \mathrm{C}$ with a mobile phase of $o$-phosphoric acid $0.1 \%(\mathrm{v} / \mathrm{v}) \mathrm{pH}$ 6.0 adjusted by addition of triethylamine:acetonitrile $(45: 55, v / v)$, run at a flow-rate of $1.0 \mathrm{~mL} \mathrm{~min}^{-1}$, and using PDA detection at $240 \mathrm{~nm}$. The injection volume was $20 \mu \mathrm{L}$ and the quantitation was performed using absolute peak area.

\section{RESULTS AND DISCUSSION}

In our previous research paper, ${ }^{14}$ we reported a validated LC method for the determination of NTZ in pharmaceutical formulations, but the development of a more convenient, simple, less time-consuming and economical direct UV-spectrophotometric method for routine analysis of NTZ in pharmaceutical formulations is highly desirable.

In this work, different solvents were investigated to develop a suitable UV-spectrophotometric method for the analysis of NTZ in coated tablets and powder for oral suspension. For selection of diluents, the criteria employed were the sensitivity of the method, the easiness of the sample preparation, and the solubility of the drug.

NTZ is poorly soluble in ethanol and methanol, practically insoluble in water, but freely soluble in acetonitrile. By using methanol and ethanol in different proportions as diluent low precision in the drug solubilization was founded. Acid $(\mathrm{HCl} 0.1 \mathrm{~N}$ and $0.01 \mathrm{~N})$ and basic $(\mathrm{NaOH} 0.1 \mathrm{~N}$ and $0.01 \mathrm{~N})$ solutions were tested. We found that in acid solution the drug has low solubility. In basic diluents the drug has good solubilization but does not maintain stability. Finally, acetonitrile was used as a first diluent was used because of the total solubilization of the drug in this diluent and its accuracy in results. In order to reduce the use of organic solvent, water at $\mathrm{pH} 4.5$ (adjusted with $o$-phosphoric acid $10 \%$ ) was used as diluent. The drug stability studies were accomplished in each solvent for the development and validation of the method. The stability of NTZ in acetonitrile and water at $\mathrm{pH} 4.5$ was evaluated to verify if any spontaneous degradation occurs when the samples are prepared. The data obtained showed that sample solutions were stable during $3 \mathrm{~h}$ when stored at room temperature. Apparent molar absorptivity of the drug was found to be $15.7 \times 10^{3} \mathrm{~L} \mathrm{~mol}^{-1} \mathrm{~cm}^{-1}$ in water at $\mathrm{pH} 4.5$ and at $345 \mathrm{~nm}$.

Before applying an analytical method it is mandatory that we validate it. The validation testifies that the procedure it suitable for 
Table 1. Precision results of UV-spectrophotometric assay of nitazoxanide in tablets and powder for oral suspension

\begin{tabular}{lccc}
\hline Dosage forms & Day 1 $(n=6)$ & Intra-day precision & Inter-day precision a \\
& mean \pm RSD $\%$ & $\begin{array}{c}\text { Day 2 }(n=6) \\
\text { mean } \pm \text { RSD } \%\end{array}$ & $\begin{array}{c}\text { Day 3 }(n=6) \\
\text { mean } \pm \text { RSD } \%\end{array}$ \\
\hline Tablets & $100.48 \pm 0.58$ & $99.16 \pm 0.50$ & $100.38 \pm 0.56$ \\
Powder for oral suspension & $100.2 \pm 0.91$ & $100.13 \pm 0.99$ & $101.16 \pm 1.07$ \\
\hline
\end{tabular}

Data expressed as mean of three days.

the intended purpose. The analytical method was validated in relation to parameters such as linearity, specificity, precision, accuracy, and robustness. ${ }^{19,20}$

The linearity was established by least squares linear regression analysis of the calibration curve. The regression equation for NTZ was found by plotting peak absorbance $(y)$ versus concentration $(x)$ in the range of $2-20 \mu \mathrm{g} \mathrm{mL}^{-1}$. The representative linear equation was $y=0.0524 x+0.0016$, and the correlation coefficient $(r=0.9999)$ was highly significant. The validity of the assay was verified by means of ANOVA (SAS 6.11 for windows, SAS Institute Inc. CARY, NC, USA), which demonstrated significant linear regression:

$F_{\text {calculated }}=204931>F_{\text {critical }}=4.75 ; p<0.05$

and no significant linearity deviation:

$F_{\text {calculated }}=1.45<F_{\text {critical }}=3.26 ; p<0.05$

The specificity test demonstrated that there was no interference in the determination of the drug. The UV-spectrum of NTZ was not changed in the presence of common excipients, used in the formulation of coated tablets and powder for oral suspension, in the $\lambda_{\text {max }} 345$ $\mathrm{nm}$ of NTZ. As shown in Figure 2, the excipients present functional groups that absorb in the UV wavelength range of $200-250 \mathrm{~nm}$, in the tested conditions.

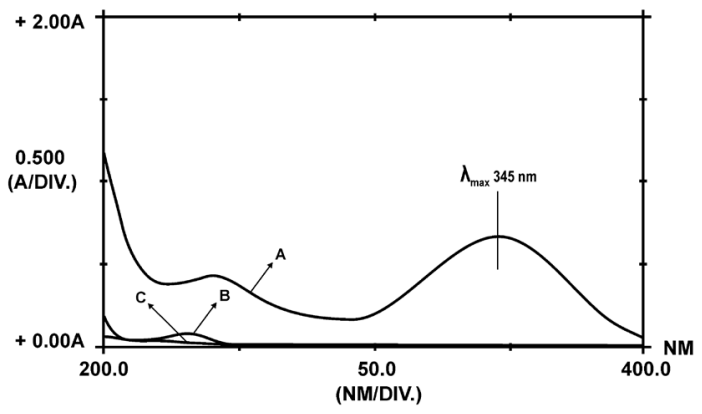

Figure 2. UV spectrum obtained through the analysis of nitazoxanide standard solution (A), placebo solution of powder for oral suspension (B), and placebo solution of coated tablets $(C)$

Precision was determined by studying the repeatability and intermediate precision. The experimental values obtained for the determination of NTZ in samples are presented in Table 1. The precision results (RSD $\%$ ) of the assay were $0.58,0.50$, and $0.56 \%$ in coated tablets and 0.91 , $0.99,1.07 \%$ in powder for oral suspension. The variability of the results was low with RSD values of less than $1.1 \%$ to intra-day, and the values of inter-day was $0.73 \%$ in coated tablets and $0.57 \%$ for powder for oral suspension. RSD values found for the analytical method were within the acceptable range indicating that this method has excellent repeatability and intermediate precision. The Figure 3 shows an UV spectrum of NTZ standard solution and commercial samples solutions.

The excellent mean percentage recovery values, about to $100 \%$, and their low relative standard deviation values (RSD $\leq 1.0 \%$ ) were

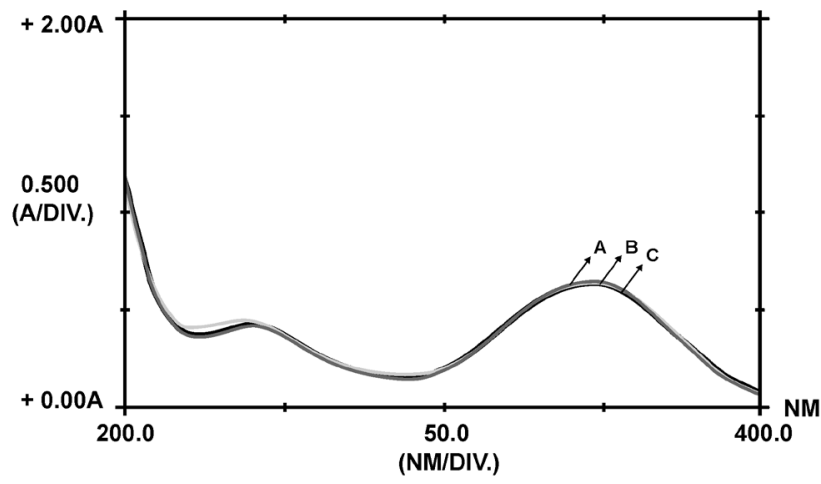

Figure 3. UV spectrum obtained through the analysis of nitazoxanide standard solution (A) and commercial samples solutions of powder for oral suspension solution $(B)$ and coated tablets $(C)$

found satisfactory. At each level of the NTZ concentration three determinations were performed. The mean recovery was $99.06 \%$ $(\mathrm{RSD}=1.0 \%)$ for coated tablets and $99.97 \%(\mathrm{RSD}=0.9 \%)$ in powder for oral suspension (Table 2). These results revealed that any small change in drug concentration in these solutions could be accurately determined by the proposed analytical method.

Table 2. Experimental values obtained in the recovery test for nitazoxanide by using the UV-spectrophotometric method

\begin{tabular}{lcccc}
\hline Dosage forms & \multicolumn{2}{c}{$\begin{array}{c}\text { Amount of standard } \\
\left(\mu \mathrm{g} \mathrm{mL}^{-1}\right)\end{array}$} & Recovery (\%) & $\begin{array}{c}\text { Mean } \\
\pm \text { RSD \% }\end{array}$ \\
& Added & Found $^{\mathrm{a}}$ & & \\
\hline \multirow{3}{*}{ Tablets } & 2.00 & 2.00 & 100.0 & \\
& 4.00 & 3.92 & 98.00 & $99.06 \pm 1.0$ \\
Powder & 6.00 & 5.95 & 99.17 & \\
for oral & 2.00 & 2.02 & 101.0 & \\
suspension & 4.00 & 3.99 & 99.75 & $99.97 \pm 0.9$ \\
\hline
\end{tabular}

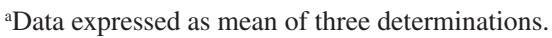

The robustness was determined with changes in the $\mathrm{pH}$. Variation of $\mathrm{pH}$ of the selected media by \pm 0.2 did not have any effect on the absorbance value of NTZ. The assay values of NTZ were found $99.34 \%$ $(\mathrm{RSD}=0.45 \%, n=3)$ in coated tablets and $99.71 \%(\mathrm{RSD}=0.35 \%, n=$ 3 ) in powder for oral suspension. The NTZ solutions (coated tablets and powder for oral suspension) in working solutions exhibited no spectrophotometric changes over a period of $3 \mathrm{~h}$ when kept at room temperature.

\section{Comparison between UV-spectrophotometric method and LC method}

The analytical methods were compared using statistical analysis. The Student's $t$-test was applied and did not reveal discrepancy between the experimental values obtained in the sample analysis by the two methods. The calculated $t$-values $\left(t_{\text {calculated }}=1.52\right.$ for coated tablets and $t_{\text {calculated }}=0.92$ in powder for oral suspension) were found 
to be less than the critical $t$-values $\left(t_{\text {critical }}=2.07\right.$ for coated tablets and $t_{\text {critical }}=2.07$ in powder for oral suspension) at $5 \%$ significance level. The developed and validated methods provided similar results for NTZ quantitation. Then, the proposed method can be applied directly and easily to the oral pharmaceutical preparations of NTZ.

\section{CONCLUSION}

This work presents a simple and validated UV-spectrophotometric method for the determination of NTZ in pharmaceutical formulations. The method was validated showing satisfactory data for all parameters tested. Thus, it offers advantages over other analytical methods due to its rapidity, simplicity, and lower cost. There is no significant difference between the previously validated LC method and UV-spectrophotometric method. Therefore, the proposed method is suitable and can be conveniently used for the routine quality control of NTZ in coated tablets and powder for oral suspension.

\section{ACKNOWLEDGMENTS}

The authors thank CAPES (Brazil) for the financial support.

\section{REFERENCES}

1. Rossignol, J. F.; Cavier, R.; Chem. Abst. 1975, 83, abstract 28216 n.

2. Raether, W.; Hänel, H.; Parasitol. Res. 2003, 90, S19.

3. Fox, L. M.; Saravolatz, L. D.; Clin. Infect. Dis. 2005, 40, 1173.

4. Cabello, R. R.; Guererro, L. R.; Garcia, M. R. M.; Cruz, A. G.; T. Roy. Soc. Trop. Med. H. 1997, 91, 701.

5. Abaza, H.; El-zayadi, A. R.; Kabil, S. M.; Rizk, H.; Curr. Ther. Res. 1998, 59, 116.
6. White, A. C.; Expert Rev. Anti Infect. Ther. 2004, 2, 43.

7. Stockis, A.; Deroubaix, X.; Lins, R.; Jeanbaptiste, B.; Calderon, P.; Rossignol, J. F. ; Int. J. Clin. Pharm. Th. 1996, 34, 349.

8. Broekhuysen, J.; Stockis, A.; Lins, R. L.; DE Graeve, J.; Rossignol, J. F.; Int. J. Clin. Pharm. Th. 2000, 38, 387.

9. Zhao, Z.; Zhang, L.; Xue, F.; Wang, X.; Zheng, W.; Zhang, T.; Fei, C.; Zhang, K.; Qiu, M.; Xin, R.; Yang, F.; J. Chromatogr., B 2008, 875, 427.

10. Kapse, G. K.; Prabhakar, G.; Appala, R. S.; Indian J. Pharm. Sci. 2006, $68,403$.

11. Gopu, C. L.; Thomas, S.; Paradkar, A. R.; Mahadik, K. R.; J. Sci. Ind. Res. 2007, 66, 141.

12. Jadhav, A. S.; Pathare, D. B.; Shingare, M. S.; Chromatographia 2007, $66,595$.

13. Rane, V. P.; Sangshetti, J. N.; Patil, K. R.; Yeole, R. D.; Shinde, D. B.; Chromatographia 2008, 67, 455.

14. Malesuik, M. D.; Cardoso, S. G.; Steppe, M.; Chromatographia 2008, $67,131$.

15. Nascimento, A. P.; Trevisan, M. G.; Kedor-Hackmann, E. R. M.; Poppi, R. J.; Anal. Lett. 2007, 40, 975.

16. Breier, A. R.; Steppe, M.; Schapoval, E. E. S.; Anal. Lett. 2007, 40, 2329.

17. Pattanayak, P.; Sharma, R.; Chaturvedi, S. C.; Anal. Lett. 2007, 40, 2288.

18. Valladão, D. M. S.; Ionashiro, M.; Netto, J. Z.; Quim. Nova 2008, 31, 44.

19. ICH; International Conference on Harmonization of technical requirements for registration of pharmaceuticals for human use, 2005.

20. USP 32; The United States Pharmacopoeia, 32 ${ }^{\text {th }}$ ed.; United States Pharmacopeial Convention: Rockville, 2009. 